\title{
Régimen objetual entre los mayas del período Clásico, una propuesta
}

\section{Objetual Regime of the Maya during Classic Period, a Proposal}

\author{
Antonio Jaramillo Arango \\ Posgrado en Estudios Mesoamericanos, UNAM
}

\begin{abstract}
Resumen: Para la arqueología académica del siglo xx los objetos fueron sólo fuentes para conocer la acción humana. Basado en recientes propuestas de teoría antropológica, este artículo propone una arqueología recursiva, esto es, incluir los conceptos de persona de los mayas del Clásico como parte del análisis para entender a los objetos como verdaderos protagonistas dentro de las relaciones sociales. Existen diferentes maneras de ser en el mundo de los objetos en el área maya identificadas en la arqueología del Clásico: personas-objetos, partes de un cuerpo dividual y máquinas. Aquí se exploran estas tres formas a través de contextos arqueológicos y textos epigráficos, procurando acercarse a la construcción de realidad de los mayas clásicos. Desde un análisis multidisciplinar que incluye arqueología, epigrafía, historia, linguística y antropología, se analiza un abundante número de ejemplos provenientes de diferentes regiones dentro del área maya que aportan un panorama general de este fenómeno.
\end{abstract}

Palabras clave: Arqueología recursiva, cuerpo dividual, régimen objetual, agencia, persona.

ABSTRACT: Within the academic archaeology of the twentieth century, objects were only considered as sources for understanding human action. Based on recent theoretic anthropological proposals, this paper proposes a recursive archaeology, that is, to include the Classic Maya concepts as part of our analysis in order to understand objects as real protagonists in social relationships. In the Maya area, objects have different ways of being in the world which have been identified by the archeology of the Classic period: person-objects, parts of a dividual body and machines. These three ways are explored here through archaeologic contexts and epigraphic texts with the aim of approaching the construction of reality of the Classic Maya. With a multidisciplinary analysis that includes archaeology, epigraphy, history, linguistics and anthropology, a high number of examples coming from different regions in the Maya area is examined. Thus, an overall view of this phenomenon is presented.

KEYwords: Recursive archaeology, dividual body, objetual regime, agency, personhood.

RECEPCIÓN: 13 de febrero de 2015.

ACEPTADo: $1^{\circ}$ de junio de 2015 .

DOI: $10.19130 /$ iifl.ecm.2016.48.752 


\section{Objetos e interpretación arqueológica}

Siguiendo la tradición humanista, la arqueología académica del siglo xx se propuso estudiar a los hombres a través de sus restos materiales: al ser ellos los que fabricaron los objetos, los utilizaron y/o eventualmente los desecharon o los destruyeron, el estudio de estos objetos nos sirve para reconstruir algún aspecto de su vida social. De esta manera, los humanos hemos sido el objeto de conocimiento de este tipo de arqueología. Aunque esta ha sido la tendencia general, no ha habido una sola manera de tratar a las fuentes arqueológicas; como punto de partida de este escrito voy a exponer el tratamiento que le dieron a los objetos dos de las corrientes teóricas más importantes de la arqueología del siglo xx: el difusionismo y el procesualismo, para luego proponer una alternativa basada en los mayas del período Clásico.

En la década de los años treinta del siglo pasado, Alfred Louis Kroeber (1939: 4) propuso que se necesitaba una antropología holística para entender el complejo entramado cultural. Para este autor norteamericano la "cultura" se definía precisamente por la combinación de aspectos materiales, no materiales y medioambientales, algo que él mismo llamó "todos culturales". Siguiendo esta propuesta, los antropólogos difusionistas definieron las sociedades que estudiaban a partir de una serie de rasgos en la que, como sugirió Kroeber, se mezclaban estos tres tipos de aspectos (por ejemplo Bennet y Bird, 1949; Kirchhoff, 2009 [1943]). Aplicada al pasado precolonial americano, esta postura inspirada en el difusionismo se enfrentó a una gran dificultad: al contar mayoritariamente (no sólo) con fuentes materiales, para los difusionistas, la cultura de los pueblos precolombinos se fue reduciendo a su expresión material. Así, objetos precolombinos y cultura precolombina se confundieron y se convirtieron en sinónimos, al llegar al punto de que muchos objetos arqueológicos ganaron identidad étnica. Aún hoy es común oír o leer sin hesitación sobre piedras mexicas, objetos de oro quimbayas o cerámica moche.

Este es uno de los aspectos clave que justo alienta la crítica de los procesualistas a la metodología del difusionismo. Para el procesualismo la cultura no puede ser definida por una lista de rasgos, pues se corre el peligro de caer en la confusión de identificar los objetos prehispánicos con la cultura de quienes los produjeron. Como su nombre lo indica, para esta escuela son los procesos sociales los que estarían definiendo a una cultura, y, por tanto, los objetos no serían sino la expresión material de los procesos sociales (Renfrew y Bahn, 1998: 469-478). Aunque queda saldada la posible identificación de cultura exclusivamente con la materialidad, los objetos siguieron siendo apenas fuentes de la acción humana.

\section{Sociología del objeto}

A finales del siglo xx surgieron varias propuestas que tuvieron como finalidad pensar los objetos en la Antropología y la Historia desde una perspectiva dife- 
rente. Con el compromiso de ser conscientes de que los objetos significaban algo muy diferente según la cultura que les daba sentido, especialistas de varias disciplinas trataron de manera sociológica los usos y significados de los objetos a través del tiempo y en diferentes colectivos.

Uno de los trabajos más recordados de este grupo de investigaciones es el volumen conjunto coordinado por Arjun Appadurai titulado La vida social de las cosas. Perspectiva cultural de las mercancías. En este libro varios antropólogos e historiadores investigaron la construcción de valor en distintas sociedades, proponiendo una ampliación de la idea de mercancía de Marx y de los primeros economistas políticos (Appadurai, 1991: 78). Si bien la idea fue contextualizar a los objetos en su propia esfera de producción, intercambio y consumo, los objetos y sus significados dependían de las relaciones sociales humanas para cobrar sentido.

En arqueología, el libro de Alfred Gell titulado Art and Agency (1998) es el más utilizado para plantear la agencia de algunos objetos. Este autor propone que los objetos, generalmente conceptualizados sólo como pacientes de la agencia humana, pueden adquirir un tipo de agencia dependiendo de situaciones específicas. La agencia, definida por Gell como "causar que eventos ocurran" (1998: 16) puede ser transmitida por los seres humanos a los objetos. Para demostrar este punto, Gell distingue entre dos tipos de agencia: una primaria que es ejercida por seres con intención (humanos y algunos animales), y una secundaria, en la que ciertos seres y objetos ayudan a extender y distribuir la agencia de los seres con intencionalidad (ibid., 20). De esta manera, podemos apreciar que, según este autor, son los seres humanos quienes dotan de agencia a algunos objetos y en cierta medida los objetos se subordinan a la "agencia primaria" de los seres con intencionalidad. La propuesta de Gell fue una gran ruptura con las anteriores conceptualizaciones teórico-metodológicas y abrió la discusión que desembocaría en una teoría antropológica de los objetos que tomara en cuenta el papel de estos en las relaciones sociales.

Los trabajos de Appadurai y Gell, entre otros, ${ }^{1}$ apoyaron la idea de un multiculturalismo en el que los objetos adquirían un significado diferente dependiendo de las concepciones humanas que se tuvieran de éstos. No sería sino hasta el surgimiento de una crítica a estos trabajos que se planteó la idea de que existían otras realidades tan reales como la de la tradición euroamericana y que los objetos podían ser parte de éstas, superando así la idea, todavía antropocéntrica, de la existencia de un mundo natural y diferentes concepciones humanas sobre éste. ${ }^{2}$

\footnotetext{
${ }^{1}$ Podrían sumarse a este análisis los trabajos de Pierre Bordieu (1997: 93-94) sobre la importancia de los objetos en la reproducción social y de Ian Hodder (2012: 10-14) sobre la conceptualización de las cosas como entidades discretas que mantienen siempre conexiones con otras entidades.

${ }^{2}$ Hago esta revisión sobre la conceptualización de los objetos en la arqueología académica del siglo xx, incluyendo lo que he decidido llamar como la "sociología del objeto", no por un afán enciclopédico o el requerimiento abstracto de un "estado de la cuestión". Lo hago porque considero que todas estas concepciones siguen vigentes a diferentes niveles y con diferentes grados de intensidad en la concepción que los arqueólogos y no arqueólogos tienen de los objetos. En ese sentido mis
} 


\section{Contra la tiranía del sujeto}

Para superar una teoría objetual meramente sociológica y multiculturalista fue necesaria una crítica al dualismo entre sujeto y objeto. La disolución entre sujeto y objeto puede plantearse desde diferentes perspectivas (Miller, 2009: 5-7); me parece importante, sin embargo, resaltar el planteamiento de la antropología relacional (Strathern, 1995). Según este tipo de antropología no existen identidades de objetos y sujetos a priori, sino que se definen precisamente por su posición dentro de una relación. Así, un mismo elemento (llámese humano, vegetal, animal o artefacto) puede ser el sujeto agente en una relación específica, y en otro sería el objeto paciente. Desde tal perspectiva, sujeto y objeto no son identidades sustanciales, sino cualidades adquiridas gracias a una relación, lo que hace más flexible la oposición dual entre ambas categorías.

La discusión teórica sobre la disolución del dualismo sujeto-objeto ha fructificado en diversos trabajos antropológicos sobre materialidad en casos específicos. A continuación expongo algunos destacados.

Bruno Latour es uno de los autores más difundidos que no sólo incluye en su análisis la agencia vista desde la perspectiva relacional (superando la distinción sustantivista entre sujeto y objeto) sino que propone una metodología epistemológica amplia: la teoría Actor-Red (2008). Para Latour, en el análisis de las diferentes sociedades, incluyendo la europea, hay que reconocer la agencia de humanos y no humanos y de esta manera tratarlos con el mismo sentido epistemológico: como actantes.

En el marco de la antropología americanista, los trabajos que adoptan una postura relacional analizan los objetos con otras aristas. Aceptando que la concepción de una persona individual es una aparición reciente en la tradición euroamericana y que son más comunes las personas dividuales — compuestas por una variedad de relaciones que exceden un solo cuerpo indivisible-, tal y como propuso Marilyn Strathern para Nueva Guinea (1988: 13), algunos antropólogos americanistas (sobre todo amazonistas) han investigado cómo es la construcción de las personas humanas y no humanas desde la perspectiva amerindia. En América predomina la idea de que los seres son una construcción con elementos previos y no fruto de una creación ex nihilo (Viveiros de Castro, 2004: 477-478), por lo que los seres no son creados en un momento fijo, sino construidos en una dinámica que puede ser constante y llevada a cabo durante toda la vida. La construcción de seres incluye, entre otras cosas, la incorporación de objetos a su cuerpo. Este planteamiento ha llevado a que muchos trabajos hayan comentado el papel que juegan los objetos en la construcción del cuerpo de las personas amerindias (Santos-Granero, 2009; Lagrou, 2012; Neurath, 2013; Pitarch, 2013).

Estoy alerta de un peligro que tiene la perspectiva relacional que ha sido expuesto de modo magistral por Daniel Miller (2009): se corre el riesgo de sustituir

argumentos se posicionan tomando en cuenta tales posturas. 
términos como cultura o sociedad por el concepto de "relación social", que pretende ser la finalidad de la explicación antropológica y por ende no necesita, a su vez, ser explicado. Para conjurar este peligro quiero definir bien los vocablos que voy a emplear. Persona, idea que no coincide con la de humano, se refiere a la singularización de un ser, no necesariamente individual, dentro de un colectivo sin la necesidad de oponerse a este o replicarlo. Para efectos prácticos, yo utilizo "persona" para referirme a aquellos actantes que entran en una relación con posibilidad de intencionalidad y capacidad de decisión. El cuerpo no puede ser separado de manera conceptual de la persona, pues es en y a través del cuerpo que las personas construyen las relaciones sociales que las integran en su colectivo (Martínez, 2009: 246). Con relación social me refiero a la interacción, normada o no, y a diferentes escalas, entre personas (humanas y no humanas), siendo estas mismas personas dividuales y complejas en su constitución (con elementos humanos y no humanos). Lo fundamental aquí no es ver la relación entre personas o entre personas y objetos, sino entender a personas y objetos como relaciones (Strathern, 1995: 19).

El solo hecho de querer dar definiciones generales conlleva otro riesgo. Parece impositivo imponer un concepto de "persona" a un grupo específico con sus propias dinámicas y parecería por tanto más recomendable tomar una idea derivada de las prácticas locales que se pueda traducir como "persona". Aunque reconozco las ventajas de buscar términos nativos que sean más precisos que las traducciones que podamos construir, en este artículo me gustaría recorrer el camino inverso. En vez de buscar un vocablo en una lengua indígena (en el caso que nos ocupa, una lengua maya) que pueda ser traducido como "persona", pretendo investigar qué seres concretos crean relaciones que los constituyen como "actantes que entran en una relación con posibilidad de intencionalidad y capacidad de decisión". Aunque es el mismo concepto de persona el que aplico, en la tradición euroamericana y en la maya éste se refiere a materialidades, cuerpos y realidades diferentes. Dicho de otra manera, la persona euroamericana y la maya "...no son sinónimos que deben conjugarse, sino homónimos que deben separarse” (Viveiros de Castro, 2013: 69).

\section{Arqueología recursiva}

En años más o menos recientes se ha planteado una metodología que hace explícito que la antropología es una coproducción entre los investigadores y los pueblos a los que supuestamente estudia. Esto ha sido llamado, con algunos matices, antropología recursiva (Neurath, s.f.: 1), antropología indígena (Pitarch, 2013: 11-16) o teoría nativa (Martínez, 2012: 39). Según esta antropología, vale la pena tomar en cuenta y revalorar los conceptos con los que las personas de las sociedades que estudiamos crean su mundo. Si los aportes de la antropología recursiva han mostrado grandes beneficios en el análisis de sociedades actuales, sobre todo al incluir al otro como coautor de la teoría antropológica, valdría la pena pensar en una arqueología recursiva. Considero que una forma de escapar 
del antropocentrismo que ha acompañado a la arqueología durante el siglo xx es, precisamente, incluir en el análisis cuestiones y conceptos nativos que expandan los marcos desde los que planteamos los estudios académicos.

La arqueología recursiva presenta una desventaja obvia con respecto a su contraparte etnográfica: muchos de los actantes que participaron en las relaciones sociales - los seres humanos, las plantas y los animales- están muertos y no podemos interactuar con ellos. No obstante, este tipo de actantes dejan algunos restos materiales muy valiosos y, sobre todo, contamos con los objetos fabricados en materiales no perecederos.

A diferencia de lo que ocurre en la antropología sobre sociedades actuales, donde una queja recurrente de quienes se ocupan de la materialidad es el olvido en el que ha caído el análisis de los objetos (Henare, Holbraad y Wastel, 2007; Miller, 2009; Santos-Granero, 2009), en la arqueología mayista la abundancia de objetos es la regla. Sin embargo, por las causas que ya apunté, en la arqueología académica del siglo xx y en el tratamiento que hace ésta de los objetos, los estudios mayas no han estado exentos del antropocentrismo humanista. Más allá de enunciar los efectos negativos de usar los objetos tan sólo como fuentes de la acción humana, vale la pena dar una alternativa.

Podemos identificar muchas sociedades en las que los objetos participaron en relaciones sociales que incluyeron personas humanas y no humanas: en ocasiones como personas autónomas y diferenciables, y en otras como parte dividual del cuerpo de una de ellas. Como intentaré demostrar, los mayas del Clásico son un caso más en donde esto también ocurre. Así, procuro no comprender a los objetos tan sólo como fuentes de información de la acción humana, sino, al tratarlos como personas, entenderlos como un índice de las relaciones sociales en las que estuvieron insertos y, al mismo tiempo, como la cristalización de fuerzas relacionales que pueden ser analizadas a través de su materialización (Lagrou, 2012: 3). Dicho de otro modo, los objetos son condensadores de historias de interacciones sociales. Esto lleva a apreciarlos como ellos mismos se presentan, no asumiendo automáticamente que representan, significan o simbolizan algo más, sino que materializan un mundo que, en el caso de los estudios antropológicos y arqueológicos, es radicalmente diferente al nuestro (Henare, Holbraad y Wastel, op. cit., 1-31). Para el caso de la arqueología maya contamos con la enorme ventaja de tener una escritura glotográfica que hace a algunos objetos tener su propia voz, sólo basta con tomar en serio lo que nos dicen. Utilizar los objetos para desplegar las relaciones sociales de los mayas del Clásico es una excelente oportunidad para acceder a su construcción de realidad y poder, aunque sea apenas un comienzo, plantear una arqueología recursiva en esta región.

\section{Objetos que no son objetos descritos en la etnografía mayista}

Una primera alerta de que los objetos no son lo mismo en la tradición euroamericana y en la tradición maya nos la da la etnografía. Mucho se ha discutido de las 
ventajas y deformaciones de lo que se ha llamado la "comparación etnográfica" para interpretar el pasado precolonial americano. Aunque este delicado equilibrio debe verse como una doble vía interpretativa, en los estudios mesoamericanos impera una falsa lógica: el entendimiento del pasado nos ayuda a interpretar el presente. Esto ha llegado al absurdo de convertir el pasado prehispánico en un "deber ser", frente al cual las etnografías actuales deberían comprobar qué tanto los pueblos actuales se han desviado de este ideal. Precisamente a esto es a lo que Pedro Pitarch llama el "canon prehispánico" (2013: 209-231). Desde el punto de vista metodológico es más conveniente proceder de un contexto más conocido a uno que lo es menos. En el caso que nos atañe, del presente etnográfico al pasado precolonial. Más que extrapolar bloques enteros de interpretaciones, creo que las analogías deben ser alertas que nos indican dinámicas diferentes que deben ser comprobadas de modo contextual. En este proceso siempre es importante hacer comparaciones controladas con unidades temáticas semejantes y pendientes a posibles casos de disyunción (Oudijk, 2008: 126).

Volvamos a la argumentación principal. He percibido en algunas etnografías mayas que hay tres formas de ser en el mundo de los objetos: objetos-persona, objetos como parte de un cuerpo dividual y máquinas. Aquí expongo algunos ejemplos de estos tres casos, tomando ejemplos etnográficos que provienen de diferentes regiones del área maya para reforzar la idea de que esto no es la particularidad de un grupo específico, sino que es en cierta medida compartido en la zona.

Es común encontrar en las etnografías mayas que diversos objetos tienen en algún grado una "fuerza vital" y gracias a esto se configuran como objetos-persona. En Santiago Atitlán, en los altos de Guatemala, los mayas tz'utujiles son especialmente explícitos en esto. Allen J. Christenson comenta que los objetos que participan en ciertos rituales tienen k'u'x, “corazón”. Esta es la misma fuerza vital que poseen los antepasados y los santos (Christenson, s.f.), y le da a estos objetos la posibilidad, al igual que a santos y antepasados, de entablar parentesco e insertarse en las relaciones sociales como personas. Sobre la misma comunidad Matin Pretchel y Robert Carlsen comentan que los tejidos no sólo se entrelazan sino que en realidad nacen (1988, citado en Hendon, 2012a: 87), adquiriendo del mismo modo relaciones genealógicas con quienes los engendran.

Además de ser personas, los objetos pueden ser parte de un cuerpo personal dividual. Pedro Pitarch (op. cit.) señala que el cuerpo tzeltal se compone de dos tipos de cuerpo, el cuerpo carne y el cuerpo presencia. El segundo de estos es construido y se va constituyendo a través de la vida de la persona. Uno de los aspectos que forma de manera integral este tipo de cuerpo es material: el vestido. Tanto así que desde la perspectiva tzeltal no tiene sentido mostrar un vestido si no es envolviendo un cuerpo, pues las ropas constituyen en realidad una segunda piel (ibid., 30). Un dato linguístico apunta a que esta construcción del cuerpo no es sustantivista (acumulando cosas y comportamientos), sino relacional. Varias lenguas amerindias, y entre ellas las lenguas mayas, tienen dos tipos de posesiones: alienables e inalienables. Las posesiones inalienables son aquellas que no 
pueden ser conceptualizadas independientemente de quién o qué las posee. En maya mopán (Schumman, 1997: 95), en maya yucateco (Lehmann, 2002: 35) y en tzutujil (Dayley, 1985: 145), en lo referente a las personas, las posesiones inalienables se refieren a algunas partes del cuerpo carnal (su sangre, sus huesos) y también a algunas relaciones de parentesco (sus descendientes, sus ascendentes). En tzutujil esto se expande a todos los sustantivos que tienen una relación intrínseca con la persona, incluyendo a los objetos (Dayley, id.). Aunque no se explicita en tales ejemplos que esto obedezca a una construcción de la persona, sí está indicando que en la construcción de un cuerpo (con sus partes, su parentesco y hasta con objetos que le son intrínsecos) es más importante el establecimiento de relaciones que la acumulación sustantiva de partes, remitiéndonos de nuevo a la definición de persona dividual ya citada (Strathern, 1988: 13).

Pero también hay objetos que no están ligados constitutivamente a las personas. Los mayas tienen auténticas máquinas que, al igual que las de la tradición euroamericana, sirven para, mediante una técnica específica, poder manipular el mundo material. En la península de Yucatán, en la región circundante a Oxkutzcab, William Hanks hace una excelente descripción del ritual terapéutico de un shaman maya. Para equilibrar las fuerzas buenas y malas de un paciente, el shaman tiene que citar a una serie de espíritus (Hanks, 1986: 230-231). Para este fin, usa una máquina que activa mediante una técnica específica: él toma una mesa (un altar) y ata sus patas abriendo una autopista por los cuatro puntos cardinales, camino que han de recorrer los espíritus (Hanks, op. cit., 243). Más allá de lo que nos ilumina este ritual de la relación con la alteridad y la posibilidad de copresencia entre los mayas yucatecos, quiero hacer hincapié en la parte material del ritual. La mesa como máquina y el acto de atarla como técnica son indispensables para la manipulación controlada en una cuestión práctica, en este caso, la "salud" del paciente.

Pero iestos tres tipos de objetos (objetos-persona, constituyentes de un cuerpo dividual y máquinas) pueden encontrarse en la arqueología maya del período Clásico? Creo que una atenta revisión de los objetos arqueológicos desde la perspectiva relacional puede darnos una respuesta positiva.

\section{Propuesta de régimen objetual de los mayas del período Clásico}

Vale la pena hacer una revisión del régimen objetual entre los mayas del Clásico, es decir, de las diferentes maneras de ser objeto en este momento y en este lugar. Gracias a los datos y conceptos proporcionados por la antropología relacional en general, la amerindia en concreto y más específicamente la maya, se puede tener una idea de qué y cómo investigar. Tomar en cuenta los objetos dentro de las relaciones sociales y no como meras fuentes para conocer a los humanos es un esfuerzo que ya se ha emprendido en los estudios mayistas. Existen por lo menos tres antecedentes notables: un artículo de David Stuart (1996) sobre las estelas y las imágenes de los gobernantes mayas, los trabajos de Susan Gillespie relativos a 
la "persona social" y la "casa" (2001), y a los "aspectos corporativos de la persona" (2008), y la propuesta de Julia Hendon (2012a) respecto a la noción de "objetos como personas". En vez de exponerlos, voy a apoyarme en estos tres autores a lo largo de toda la propuesta para así poder desarrollar mis propios argumentos.

Separaré la exposición en diferentes apartados: una corta introducción aclaratoria - "personas y humanos" - y tres temas generales: "objetos persona", "persona dividual" y "máquinas", que se corresponden con los tres casos diferentes que vimos en el apartado anterior. De los tres, sólo el segundo tiene subapartados con el fin de distinguir algún aspecto en específico. Así, en "persona dividual" incluyo "personas complejas, cuerpos complejos", "enterrando al cuerpo" y "alteridad constituyente".

No obstante, me gustaría hacer explícito que no creo que estos apartados constituyan categorías de una taxonomía cerrada. De manera formal, los apartados se parecen más a listas que a categorías, pues no comparten un criterio común. Esto se debe a la enorme flexibilidad que para estar en el mundo adquirían los objetos entre los mayas del Clásico; a un reconocimiento de que la distinción es meramente un formalismo que nos hace más cómodo el análisis pero que no operaron como conjuntos abstractos y coherentes dentro de las relaciones que se enmarcaron, y, para finalizar, a un esfuerzo mío por desustancializar las relaciones sociales para poder apreciarlas en su complejidad. Todo esto redunda en que estas listas no pretenden agotar todo el régimen objetual de los mayas del Clásico y a la invitación para estar atentos a que el mismo objeto que puede entrar en una lista puede estar en otra si la relación en la que está involucrado cambia. El tránsito de un objeto entre relaciones sociales en las que podría adoptar nuevas posiciones relacionales se debe a circunstancias específicas que involucran a varios tipos de seres y no sólo a la acción premeditada ("una activación") de un humano sobre éste.

\section{Personas y humanos}

La epigrafía y la arqueología mayas han tenido múltiples problemas al tratar de identificar persona con ser humano. Quizás el ejemplo más conocido es el de K'inich Janaab' Pakal de Palenque; aunque nuevos estudios osteológicos han reconciliado la edad de muerte del cuerpo humano de la tumba del Templo de las Inscripciones con la atribuida a Pakal en los textos (Gillespie, 2008: 73), este personaje sale en el tablero del Templo XXI realizando un acto de autosacrificio con sus nietos dos décadas después de su muerte (González y Bernal, 2012). En Copán la tumba que tenía el nombre del fundador de la dinastía de la Cabeza del Murciélago, K'inich Yax K'uk Mo', contiene en realidad a una mujer. En Calakmul, una tumba en la que se indica que su ocupante es Yuknoom Yich'aak K’ahk, alberga un cuerpo que murió después de que su deceso fuera registrado en Tikal. Podría sumarse que también se registró en las inscripciones que este mismo personaje estuvo celebrando el fin del k'atun 13 (9.13.0.0.0) en La Corona 
(Stuart, 2012a: 3-4), mientras que la osamenta demuestra que el ser humano de la tumba sufría una penosa enfermedad en la columna vertebral que le haría imposible participar en festividades públicas y menos transportarse largas distancias (Suzuki, Tiesler y Cucina, 2011: 1078). Otro gobernante de la dinastía de la Cabeza de Serpiente y antecesor de Yuknoom Yich'aak K'ahk, "Testigo del Cielo", aparece ordenando un ataque a Palenque en 599 en la escalera jeroglífica de esta última ciudad (Bernal, 2011: 49-51); no obstante, conocemos que para esta fecha "Testigo del Cielo" no estaba gobernando desde hacía por lo menos veintisiete años y lo más probable es que estuviera muerto (Martin y Grube, 2008: 104). En Yaxchilán, el gobernante conocido como "Pájaro Jaguar IV" falleció a los 59 años, mientras que los análisis osteológicos arrojaron que su cuerpo carnal tenía de 30 a 35 años al momento de su muerte (Gillespie, 2008: 74)

Todo esto indica que persona y humano no eran sinónimos en el área maya en el período Clásico. Los objetos, como intentaré demostrar, jugaron un papel importante en distinguir estas dos categorías.

\section{Objetos persona}

Es bien conocida una costumbre que era común entre los mayas precolombinos pero que hoy en día nos parece extraña: muchas veces se "mataba" a algunos monumentos. De manera recurrente estatuas, esculturas, vasijas, figurillas y estelas se encuentran con personajes decapitados, narices rotas, caras borradas o simplemente agujereados como si tuvieran una herida mortal. Estos ataques a objetos fueron producto de acciones intencionadas en el pasado prehispánico, pues son demasiado recurrentes y aparecen en contextos tan variados que parece poco probable que fueran fruto de la casualidad o el paso del tiempo. Quién, cómo, cuándo y por qué se dieron estas "matanzas" de objetos son preguntas que difícilmente se puedan responder debido a la naturaleza del registro arqueológico; independientemente de dónde y cuándo se produjera, lo cierto es que en algún momento una persona decidió "matar" a uno de estos objetos. El hecho de tener la necesidad de "matar" a un objeto indica la agencia, la intencionalidad, la autonomía y el daño que puede hacer un objeto-persona sobre otras personas. En diferentes latitudes del continente también se han registrado pueblos que decidieron romper de manera intencional los objetos cuando ya no les fueron útiles por miedo al daño que pudieran causar gracias a su agencia (Cavalcante Gomes, 2010: 228).

Por fortuna, tenemos un contexto mucho mejor documentado de objetos-persona que fueron "matados" en época precolombina: los incensarios con imágenes de Gl. Éstos, que eran nombrados en los textos como los "veinte varones de Gl", fueron colocados en los nichos de la escalinata del Templo de la Cruz de la ciudad de Palenque. Al final de un k'atun, los incensarios morían, sus cuerpos eran rotos y eran enterrados en la base del templo. Lo interesante es que arqueológicamente se han encontrado falanges humanas junto a los incensarios rotos, lo que es 
comparable a la existencia de enterramientos de niños que contienen falanges de sus madres. Si, como propone el epigrafista Guillermo Bernal (2011: 202), los "veinte varones de Gl" fueron considerados hijos del gobernante palencano, vemos cómo estos objetos adquieren relaciones de parentesco que los hacen entrar como personas dentro de las relaciones sociales de su época y cumplen un ciclo vital al igual que un cuerpo orgánico.

Los incensarios tuvieron en Palenque una agencia bastante extendida: en un pasaje del tablero de las inscripciones se afirma que los incensarios de UnenK'awiil devoraron al gobernante de Santa Elena, quien había sido capturado en una guerra por Pakal en 652 d.C. (Bernal, op. cit., 101). Si bien esta escena puede entenderse como una figura retórica en el discurso, en un vaso polícromo resguardado en el Museum of Fine Arts de Boston, se aprecia cómo un incensario literalmente devora a un cautivo dispuesto sobre un altar.

Un ejemplo que pone Julia Hendon (2012a) sobre objetos-persona en Copán es el entierro del edificio conocido como Rosalila, ubicado justo en la acrópolis de Copán, debajo de la estructura 10L-16 y sobre las famosas tumbas del gobernante I y Hunal. A diferencia de otros edificios que por lo general eran destruidos cuando se construía otra estructura sobre ellos, Rosalila fue delicadamente enterrada con una ofrenda que incluía pedernales excéntricos, cuchillos de sílex, figuras de jadeíta, espinas de raya, conchas Spondylus sp., vértebras de cría de tiburón, garras de jaguar, incensarios y monumentos en piedra. Además Rosalila fue cubierta por una delgada capa de estuco que protegió la pintura y el modelado original del edificio (Argucia Fasquelle y Fash, 2005: 209). Hendon liga las ofrendas asociadas a Rosalila con ofrendas mortuorias y la capa de estuco con una mortaja blanca, al estilo en que envuelven los mayas cho'rties a sus muertos (Hendon, 2012a: 86). Vale la pena resaltar que los fardos funerarios son frecuentes en las tumbas mayas del Clásico, como en las tumbas de élite encontradas en Calakmul. El tratamiento funerario de Rosalila, análogo al que recibían los seres humanos, es el argumento que utiliza Hendon para afirmar que este edificio era una persona y era tratado como tal en Copán.

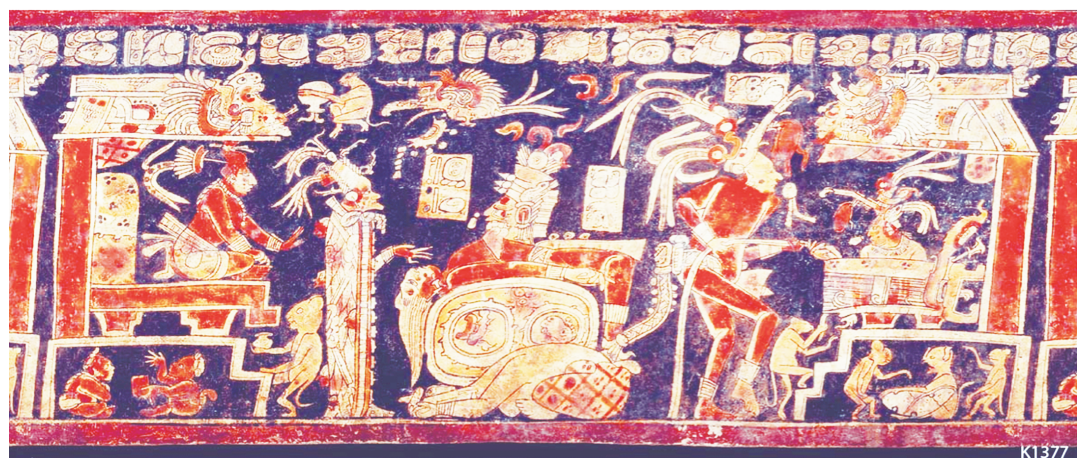

FIGURA 1. Vaso polícromo resguardado en el Museum of Fine Arts de Boston.

Tomado de Bernal, 2011: 443. 


\section{Persona dividual}

A mi juicio no basta con extender la categoría de persona a ciertos objetos. Como se aprecia en las etnografías ya citadas, el cuerpo maya es complejo y necesita ser construido. En esta construcción juegan un papel fundamental algunos objetos.

Plantear personas dividuales en el área maya no es algo especialmente nuevo, aunque por lo general se ha hecho en otros términos (con la notable excepción de Gillespie, op. cit.). Gracias a la interpretación de las vasijas polícromas y a la lectura del glifo conocido hasta hace poco como way (en la actualidad se lee wahy), se ha documentado bastante bien que animales, humanos y seres sobrenaturales podían ser considerados como compañeros. Este fenómeno no debe confundirse con la posibilidad de transformarse en animal, punto que tocaré más adelante. Ello se ha interpretado con bastante recurrencia como coesencias, en las que diferentes cuerpos comparten una misma personalidad (Houston y Stuart, 2008). Sin embargo, al conceptualizar el compañerismo entre seres como coesencias estamos validando como universal la división entre espiritual y corporal, y al mismo tiempo le estamos dando preeminencia a lo primero sobre lo segundo. La construcción de la persona maya, por lo menos en las etnografías citadas, está más definida por su corporalidad, y las relaciones sociales construidas a partir de esta, que por una esencia no material. En las inscripciones y representaciones plásticas del Clásico no existe ninguna referencia clara a que la personalidad esté determinada por características de índole espiritual, y lo que podemos apreciar es a cuerpos interactuando sin que su materialidad sea subrayada. Cabe resaltar que lo que se ha querido denominar como entidades anímicas entre los mayas del Clásico (o’hlis, b’aahis y wahyis) tienen marcadores linguiísticos que indican que son partes del cuerpo de las que se tiene control —el sufijo -is- y en ningún momento en las fuentes se señala que no posean materialidad tangible (Velásquez, 2011: 237-238). Puede entonces comprenderse a los wahy como expresiones partibles de una persona dividual (Gillespie, 2008) y así evitar endilgar una noción metafísica de "esencia" a los mayas del Clásico que no aparece explícita en las fuentes. ${ }^{3}$ Veamos otros ejemplos de cuerpos partibles que conforman una sola persona, esta vez con objetos involucrados.

\section{Personas complejas, cuerpos complejos}

Algunas estelas tienen explícito en el texto a quién "pertenecen” y están representados en ellas (humanos y no humanos). En las estelas aparece escrita la expresión

\footnotetext{
${ }^{3}$ No pretendo extenderme aquí en la propuesta del epigrafista Erik Velásquez (2011), quien asocia ciertas expresiones encontradas en las inscripciones con "ánimas”, basado en los trabajos que para el Posclásico del centro de México tiene el historiador Alfredo López Austin. Tan sólo quiero resaltar que sak b'ook(?), sak iik'aal y k'ihn, tienen traducciones poco metafísicas: sak b'ook(?), olor o aroma y sak iik'aal, viento. Sobre k'ihn, sol, tiempo, vale la pena referir al análisis de David Stuart (1996). Me atengo entonces a lo que aparece explícito en las fuentes mayas del Clásico sobre esto.
} 
u b'ah, generalmente traducida como "su imagen". Esto se debe a que en maya yucateco colonial b'ah fue registrado como "cosa semejante a otra" (Stuart, 1996: 163). Así, si en una estela aparece $u$ b'ah y el nombre de un gobernante, se interpreta como que se quisiera indicar que en esa estela aparece una imagen de este gobernante. David Stuart tiene una interpretación que va un paso más allá. En otros diccionarios mayas b'ah tiene un significado diferente: en ch'orti bah es cuerpo, persona; en yucateco actual k'oh-bah (de k'oh, "máscara") y winik-bah (winik, "ser humano") quieren decir "imagen o retrato"; en tzotzil ba es "cara". Vemos que en todos estos casos la imagen, la persona y el cuerpo pertenecen al mismo campo semántico, incluso que en ch'orti, una lengua que está mas ligada a aquella registrada en las inscripciones que otras como el yucateco, el significado refiere de manera explícita al cuerpo. Apoyando esta idea, en el diccionario ch'orti de Wisdom (1950: 577) aparece: bah: body, self, a being, a spirit ("cuerpo, uno mismo, un ser, un espíritu”). En tzutujil, la palabra "representante" es poseída de forma inalienable (como las partes del cuerpo); esto resalta que la imagen se considera como inseparable de quien se está representando (Dayley, 1985: 145). Por esto es que Stuart propone traducir $u$ b'ah no como "su imagen", sino como "su persona" o "su cuerpo" (Stuart, op. cit., 162). Las estelas serían, desde esta perspectiva, el cuerpo (y por ende parte integral de la persona) de los gobernantes y de las deidades, que no sólo están representados en estas estelas, sino que son también dichas estelas.

Teniendo en cuenta que representaciones, cuerpos humanos y personas forman parte de un mismo campo semántico, se puede proponer una interpretación a la aparente contradicción de los datos epigráficos y los arqueológicos que he expuesto más arriba. Para solucionar la supuesta paradoja, Gillespie (2001) aplica el término "persona social", en el que una persona no se configura sólo por su cuerpo sino también por sus relaciones sociales con su "casa" compuesta por sus allegados humanos. Éstas pueden mantener vigente una personalidad aunque el cuerpo esté muerto. Considero que el concepto de "persona social" tiene un inconveniente, sirve para aclarar los eventos en los que una "persona" sigue actuando luego de la muerte de su cuerpo humano, pero no al contrario, cuando se registra un deceso antes del fallecimiento del cuerpo humano de esa persona. Esto queda patente al entender que Gillespie (op. cit., 91) basa su propuesta en un ritual funerario público que se efectuaba posteriormente a la muerte física en el que se retiraba a la persona social de la sociedad; habría que preguntarse si este rito se puede hacer antes de la muerte humana. Cuando es registrado el deceso de la persona pero el ser humano no ha muerto, o se registran acciones de una persona que no pudieron ser llevadas a cabo por su cuerpo humano, como en el caso de Yuknoom Yich'aak K'ahk, el concepto de "persona social" se queda corto. En estos casos puede que quien vaya a la guerra, sea capturado, sacrificado, festeje el k'atun 13 o realice la sucesión a sus descendientes sea la persona nombrada, pero no representada por su cuerpo humano, sino por estos otros cuerpos que también son su b'ah. 
La propuesta de Stuart excede el ámbito de las estelas. Muchos gobernantes se presentan como "sus cuerpos" o "sus personas" $(u$ b’ah) de deidades, a veces como nombres, a veces como títulos. Esto se logra no sólo por medios materiales sino también inmateriales, como usar la vestimenta del dios y comportarse y ser tratado como tal. En Mesoamérica se ha tratado este tipo de construcciones como "representantes" - por ejemplo los ixiptla entre los mexica'-; sin embargo, me gustaría volver a resaltar que en algunas lenguas mayas la palabra "representante" es poseída de forma inalienable (Dayley, 1985: 145) y que imagen y cuerpo pertenecen al mismo campo semántico (Stuart, 1996: 163), por lo que al parecer no se distingue representante y representado. No pongo en duda que cuando uno de estos gobernantes registre que él es una deidad y/o se atavíe como tal, sea en efecto una deidad. No obstante, no considero que sea tan sólo una deidad; así como en América se han registrado personas dividuales con varios cuerpos construidos, también se han registrado cuerpos complejos que albergan varias personas (Taylor, 2005). No se me malentienda, no quiero decir que un ser humano tenga dos o más personalidades diferentes, sino que, en un dado caso, un mismo cuerpo puede albergar, de manera temporal, una personalidad compleja. Utilizando un concepto de Marisol de la Cadena (2010), pero en otro contexto, estas personas "no son dos, pero son más que uno". En estos casos se duplica la complejidad, una persona compleja puede albergar en su(s) cuerpo(s) otra personalidad gracias a que material y relacionalmente también es esa otra persona.

Voy a poner un caso específico que condensa toda esta complejidad con base en una lectura de David Stuart y resaltando la implicaciones que tiene, tomando a $u$ bah como su cuerpo, su persona. En la parte posterior de la Estela 4 de Copán hay un texto que narra los orígenes antiguos de la dinastía de la Cabeza del Murciélago (Reents-Budet, 2010: 51). Casi al final de la inscripción dice exactamente lo siguiente: ts'ap-ah /(T24) u b`ah/K'uy Winik Ajaw (“dios tutelar de Copán)/ Waxaklaju'n U B'aah K'awiil”) (Stuart, 1996: 164).

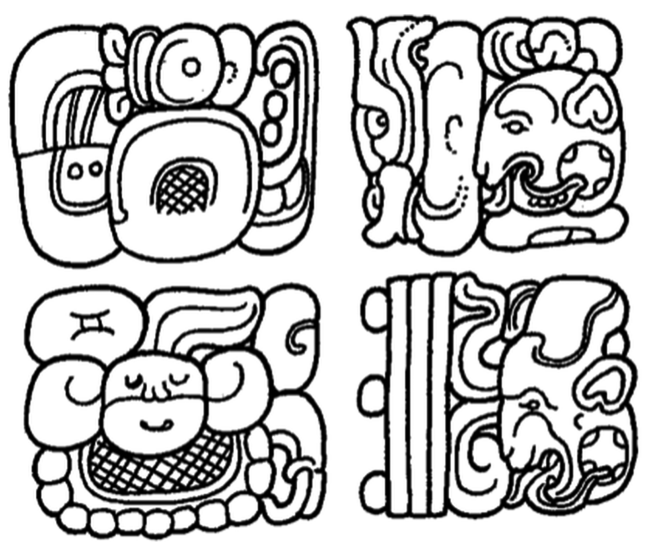

Figura 2. Texto de la estela 4 de Copán. Dibujo de David Stuart, 1996: 164. 
El texto indica que se erigió ( $\left.t s^{\prime} a p-a h\right)$ su cuerpo ( $u b^{\prime} a h$ ) de estela (siguiendo la propuesta de Stuart de que el T24 que ha sido interpretado como espejo es en realidad una estela) de K'uy Winik Ajaw (Reents-Budet, 2010: 51) quien está siendo representado por el gobernante Waxaklaju'n U B'aah K'awiil. Se puede apreciar que la expresión $u$ b'ah aparece dos veces en el texto, pero en realidad hay tres personas y dos cuerpos en esta relación. Por un lado la estela es el cuerpo, la persona, de K'uy Winik Ajaw; pero este dios está siendo personificado, temporalmente, por el gobernante copaneco. Es decir, la estela es un cuerpo de la persona compleja K'uy Winik Ajaw-Waxaklaju'n U B'aah K'awiil. El frente de la estela así lo confirma, pues se aprecia a este gobernante con atavíos del dios. Sin embargo, aunque Waxaklaju'n U B'aah K'awiil recibe por un tiempo a K'uy Winik Ajaw, su nombre nos indica que él mismo es "las 18 personas o cuerpos del dios K'awiil". Apreciemos este laberinto de cuerpos y personas complejas: un gobernante copaneco es los dieciocho cuerpos/personas del dios K'awiil y además en este caso específico adquiere un nuevo cuerpo, la estela, y se agrega a su complejidad una persona más, K’uy Winik Ajaw. Una persona compleja con por lo menos dos cuerpos, uno humano y otro de piedra (sin tomar en cuenta los 18 mencionados en el nombre de Waxaklaju'n U B'aah K'awiil).

Existen otros objetos que también sirvieron para traer la presencia de una persona a contextos donde su cuerpo humano no podía estar presente, y que quizá fueron su cuerpo objetual. Me refiero a los llamados "incensarios efigie", verdaderas esculturas de cerámica que retrataban dioses y humanos. Ya he referenciado cómo en Palenque los incensarios-dioses tejían relaciones de parentesco y además se alimentaban como un organismo viviente. En este caso me voy a referir a los incensarios en forma de figuras humanas, más concretamente a dos casos que aparecen en Copán y Quiriguá. Según las lecturas de David Stuart, el altar Q de Copán, que relata la sucesión dinástica de esta ciudad desde su fundador hasta el gobernante 16, pertenece a K'inich Yax K'uk Mo', fallecido hace cuatro siglos en el momento de dedicación del monumento. Sin embargo, en el texto se hace la precisión de que el altar no pertenece al cuerpo humano de K'inich Yax K'uk Mo', sino a su cuerpo-incensario (Stuart, 2012b). De la misma manera en la vecina ciudad de Quiriguá, el zoomorfo P registra que K'ahk' Tiliw Chan Yopaat, gobernante de Quiriguá, y Waxaklaju'n U B'aah K'awiil, gobernante de Copán, están presentes en la ceremonia de final de período de 9.18.5.0.0. Interesante es que esta ceremonia la lleva a cabo el señor de Quiriguá "Cielo Xul" justo frente al edificio que contiene la tumba de su padre, K'ahk' Tiliw Chan Yopaat, y que Waxaklaju'n U B'aah K'awiil había sido decapitado por este último. El texto de nuevo hace la aclaración de que tanto K'ahk' Tiliw Chan Yopaat como Waxaklaju'n U B'aah K'awiil están presentes bajo la forma de sus incensarios-efigie (Stuart, 2012b). La conservación, o incluso la construcción de partes del cuerpo objetual de ciertos personajes, sirvió para que estos estuvieran presentes en ceremonias y pudieran poseer monumentos cuando su cuerpo humano llevaba años muerto. Muy posiblemente la erección de monumentos y algunos rituales se llevaban a 
cabo en presencia de estos incensarios con forma humana que en realidad eran cuerpos objetuales de las personas que representaban.

\section{Enterrando al cuerpo}

La interpretación de los contextos funerarios ha sido siempre terreno fértil en las disquisiciones sobre sociedades de las que sólo conservamos restos materiales. Desde quienes ven en las tumbas la confirmación de una geografía cosmológica supuesta hasta quienes calculan las diferencias sociales basadas en la riqueza de las ofrendas, las tumbas han sido comodín interpretativo en la arqueología mayista. La abundancia de datos e interpretaciones enriquece el análisis, no pretendo aquí negar lo que se ha dicho, sino hacer la sugerencia de que con otra perspectiva se puede prestar atención a procesos poco atendidos. Antes de entrar al terreno de las interpretaciones veamos cuáles son los objetos más comunes dentro de las tumbas mayas clásicas.

Aunque en las tumbas del área maya se encuentran gran cantidad de objetos, la mayoría son objetos "utilitarios" de cerámica. Más que otro tipo de piezas, vasos, platos y vajilla en general eran enterrados con los cuerpos humanos mayas, de élite o no, característica que se extiende en toda el área maya y en casi todos los períodos de la época precolombina. También vale la pena anotar que gran parte de los objetos más valiosos hallados en las tumbas son parte de la indumentaria del personaje, como teselas y cuentas hechas de jade, turquesa o conchas preciosas. Se encuentran muchas conchas enteras y armas de sílex u obsidiana. Restos de animales, espejos, silbatos y figurillas de diferentes materiales son menos frecuentes en tumbas del Clásico. Otros materiales, aunque escasos, han dejado huella de su presencia, como son los tejidos y las plumas. Otros objetos son muy difíciles de encontrar, como grandes esculturas, sarcófagos labrados o grabados de estuco o piedra; los sonados casos de estos, parecen ser más excepciones que generalidades (Welsh, 1998). Aunque las tumbas localizadas en los lugares públicos en el área maya contienen más objetos valiosos y en general son más ricas constructivamente que aquellas que son más modestas y están en lugares residenciales, los enterramientos son similares en el tipo de objetos que se ofrendan (aunque existen varias tumbas sin ningún tipo de ofrenda). En contra de la difundida asociación que relaciona a los enterramientos en lugares públicos con tumbas fastuosas, encontramos que en Caracol, en Belice, las tumbas más ricas se encontraban en lugares residenciales y no en los públicos, dando a entender que la ostentación en los rituales mortuorios era menos centralizada que en otras ciudades del Clásico como Tikal (Chase y Chase, 1998: 327). Tampoco puede encontrarse un patrón único del tratamiento de los muertos que sea común en toda el área maya, pero sí hay ciertas generalidades que comparten las ciudades del Clásico, entre ellas, el tipo de objetos ofrendados.

Cuesta trabajo pensar que todos estos objetos tan ligados a la cotidianidad se utilizaran exclusivamente en las tumbas. Casi todos debieron ser utilizados para co- 
mer, como vestido o como armas mientras el personaje estaba en vida. Excepciones son las máscaras mortuorias y las cuentas de jade encontradas dentro de la boca.

La interpretación del estatus atendiendo a la suntuosidad de las ofrendas es muy útil para reconocer rangos dentro de la sociedad maya, aunque se queda corta a la hora de interpretar la razón de ser de los objetos ofrendados. Está claro que podemos apreciar la diferenciación social prestando atención a la riqueza de los objetos, pero como ya hemos visto, el tipo de objetos es igual en tumbas de diferentes estatus. Podría ser que los objetos cotidianos sirvieran al ser humano en su vida después de la muerte, como se ha sugerido para otras sociedades en diversos lugares del mundo y momentos históricos. Sin embargo, esta interpretación olvida un dato que me parece de especial relevancia: muchos objetos enterrados en las tumbas, sobre todo las cerámicas más utilitarias, han sido "matados", es decir, destruidos o agujereados para que pierdan su función (Martínez de Velasco, 2012). Por tanto, si van a seguir siendo utilizados post mortem no tiene sentido su destrucción.

Otro dato que nos indica que los objetos en las tumbas no eran sólo marcas de estatus social del personaje en vida o utensilios a ser usados después de la muerte es que en muchas tumbas se hallan huesos y objetos que no pertenecieron originalmente al entierro en donde fueron hallados. Esta costumbre proviene por lo menos desde el Preclásico medio; por ejemplo, en el sitio Chan en Belice, se encuentran entierros del Preclásico medio con material del Preclásico tardío, indicando una entrada a la tumba y la ofrenda de objetos y huesos posterior al enterramiento inicial (Novotny, 2013: 58). No muy lejos de allí, en Caracol, ya para el período Clásico, se encuentran huesos sueltos y objetos ajenos en tumbas de personajes de élite (Chase y Chase, 1998: 313). Esto nos revela un intercambio de material (tal vez también de objetos) entre diferentes enterramientos. Poner objetos que no pertenecieron al personaje que se enterró en el pasado indica que estos objetos no marcaban tan sólo la posición social de éste en vida, y quitar objetos de las tumbas décadas e incluso siglos después de su muerte, muestra que no eran necesarios para una vida después de la muerte.

Ya hemos visto de la mano de David Stuart que el cuerpo entre los mayas del Clásico no era sólo uno. Considero por lo tanto que las tumbas nos están indicando que al igual que en otras partes del continente, los cuerpos mayas eran construidos, entre otras cosas, por objetos. Cuando el cuerpo moría había que enterrarlo íntegramente, es decir, con todas las partes de su cuerpo construido. En ese sentido se hacía indispensable inhumar a la persona con los objetos de cerámica con los que realizaba acciones cotidianas y que incluso muchos contenían su nombre (Stuart, 1989: 151-152)

Ya vimos que entre los mayas tzeltales el vestido formaba parte integral del cuerpo; por eso no nos sorprende hallar en las tumbas clásicas vestidos y adornos corporales como conchas, collares, orejeras, entre otros. También hemos visto la presencia más o menos común de animales compañeros, lo que nos daría luz sobre los restos de animales, algunos de ellos tan feroces como cocodrilos, 
dentro de las tumbas (Chase y Chase, op. cit., 326; Wright, 2005: 91). Espejos, armas y vasijas posiblemente pertenecían a la cotidianidad de las personas vivas y se volvieron tan inseparables de su dueño que fueron considerados como parte de su cuerpo. Aunque el cuerpo carnal de una persona muriera, su personalidad podría estar presente en una de esas partes objetuales o animales de su cuerpo. Por eso, aunque a veces los objetos mantenían a una persona viva después de la muerte del cuerpo humano y conservaban sus relaciones sociales vigentes, en otras ocasiones se hacía necesario matar al resto del cuerpo, objetos o animales, para que fueran enterrados con el resto de su persona.

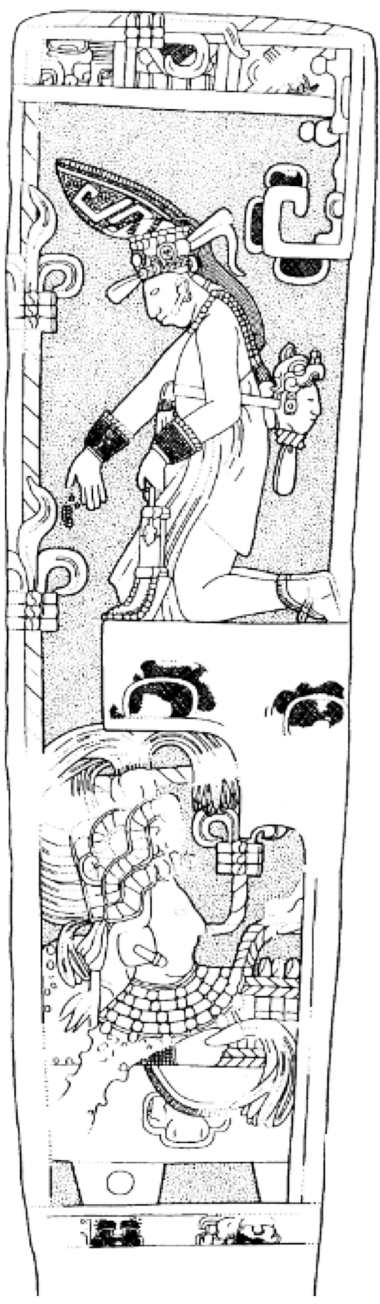

Figura 3. Estela 40 de Piedras Negras. Tomado de Martin y Grube, 2008: 149. 
Para finalizar con este punto me gustaría precisar que sabemos que los restos humanos jugaron un papel importante en la vida ritual de los vivos. Las tumbas eran abiertas y los restos humanos se retiraban de su lugar original para ser partícipes de celebraciones (Luis Fernando Nuñez, comunicación personal, 2014). Inscripciones epigráficas de diferentes ciudades, como por ejemplo Naranjo, Piedras Negras y Toniná, parecen indicar reentradas a las tumbas y la realización de rituales con el contenido de éstas (Matin y Grube, 2008: 76, 149, 150, 188) Precisamente en Piedras Negras la Estela 40 muestra una escena en la que el gobernante 4 está arrojando incienso en la tumba de su madre (Martin y Grube, id.). Los objetos de las tumbas tal vez también debieron entrar dentro de este proceso, aunque es difícil de precisar, como parte integral del cuerpo de la persona ya muerta.

\section{Alteridad constituyente}

Los mayas del Clásico gustaban de productos que reconocían como ajenos. Objetos producidos muy lejos y objetos que ya eran considerados antiguos son encontrados con relativa frecuencia en la arqueología del área maya. Éstos eran utilizados para marcar una diferencia con lo propio. En la ya mencionada Estela 4 de Copán, por ejemplo, al referirse a un tiempo antiguo de fundación, los objetos asociados a ella son igualmente antiguos (para el tiempo de erección de la estela): un altar mandado a hacer por el abuelo de Waxaklaju'n U B'aah K'awiil y una figura barrigona del Preclásico que data por lo menos del 100 d.C. (Reents-Budet, 2010: 51). En la misma ciudad, debajo de una de las residencias más importantes, la $9 \mathrm{~N}-8$, se encontraron objetos para jugar a la pelota provenientes de la costa del golfo y, a juzgar por el marcador de la cancha del juego de pelota principal de la ciudad, estos implementos eran usados efectivamente para jugar (Hendon, 2012b: 162-167). Tales objetos que refieren a una alteridad podían ser también integrales a las personas.

No ha de sorprender que encontremos objetos que refieren a alteridades que de alguna forma ayudan a relacionarse con ella. Ya hemos visto cómo el vestirse como dios ayuda a la transformación en éste. De la misma manera, en el panel del Templo XXI de Palenque, observamos a un sacerdote transformado en animal (quizá un roedor) usando una piel de jaguar; lo más probable es que esta piel ayudara al sacerdote en su transformación. En cierta medida estas mutaciones hacen de las personas sus diferentes, llámense éstos dioses o animales. De la misma manera, utilizar objetos foráneos y antiguos da la posibilidad de integrar la ambivalencia entre una alteridad exógena dañina y una endógena y benevolente, siendo la figura de contraste esencial para la integridad propia (Erikson, 1999: 346). A ello se le ha llamado alteridad constituyente y ha sido documentada para diferentes pueblos del continente (Neurath, 2008; Lagrou, 2012). Integrar este tipo de objetos en las relaciones sociales, incluso hacerlos parte del cuerpo de las personas fue una práctica común y documentada entre los mayas del Clásico, como ya he expuesto. Incluso sabemos que algunas de dichas alteridades eran 
creadas y se fabricaban objetos que parecieran antiguos o foráneos sin que realmente lo fueran. Caso patente son los objetos encontrados en ciudades como Copán, Piedras Negras, Yaxchilán y Tikal que recuerdan un cierto estilo teotihuacano, pero que sabemos que fueron creados y empleados siglos después de que la gran urbe del centro de México perdiera su esplendor (Martin y Grube, 2008: $45,129,144,208)$. Tal vez el mejor caso de la relación de la élite copaneca con lo "teotihuacano", siglos después de la decadencia de Teotihuacan, es el texto del santuario del Templo 26 de Copán; en esta inscripción, el gobernante 14 reconstruye el pasado esplendoroso de su ciudad y crea lo que al parecer es un texto bilinguie maya-teotihuacano recordando la sucesión dinástica de la ciudad. No obstante, los glifos que se usan en el texto "teotihuacano" son espurios y no representan una escritura real; con estos pseudoglifos se da la ilusión de un texto bilinguie que no pasa de ser tan sólo una puesta en escena (Martin y Grube, op. cit., 208).

Por definición de sus propios términos la alteridad constituyente se mantiene en un delgado equilibrio que no siempre es fácil de determinar. Es complicado encontrar el límite entre lo que los mayas del Clásico consideraron propio y lo que consideraron ajeno, por ende no son del todo claros los elementos exógenos que fueron incluidos como propios y qué otros fueron mantenidos explícitamente ajenos para marcar el contraste. Sin embargo reconozco en los motivos iconográficos teotihuacanos (provengan de la gran urbe del centro de México o no) esta ambivalencia propia de la alteridad constituyente, pues claramente se marca una diferencia estilística entre los elementos propios mayas y los ajenos "teotihuacanos". Hecho esta salvedad me parece acertado concluir que la alteridad constituyente fue tan importante entre los mayas del Clásico que incluso a veces tuvo que ser recreada por ellos mismos.

\section{Máquinas}

Siempre molesta la comparación entre objetos arqueológicos y máquinas. Esto parece remitir a una metáfora en la que emergen engranes y donde la acción humana es opacada por un funcionamiento mecánico ciego, sordo y mudo. Sin embargo, y como ya adelanté, la definición de máquina no implica esto. Aquí utilizaré el término máquina como un objeto que, mediante una técnica específica, sirve para extender la acción de una persona. Generalmente en la terminología antropológica y arqueológica se usan las palabras "objeto ritual" y "ritual" para referirse a lo que son operaciones mucho más prácticas que sería más preciso conceptualizarlas como "máquina" y "técnica". Desde la perspectiva euroamericana se tiende a creer que las únicas tecnologías válidas para interactuar con el mundo material son las propias, mientras que las demás tecnologías quedan condenadas a una aproximación esotérica. Sin embargo, durante el Clásico, en el área maya abundaban las máquinas. 


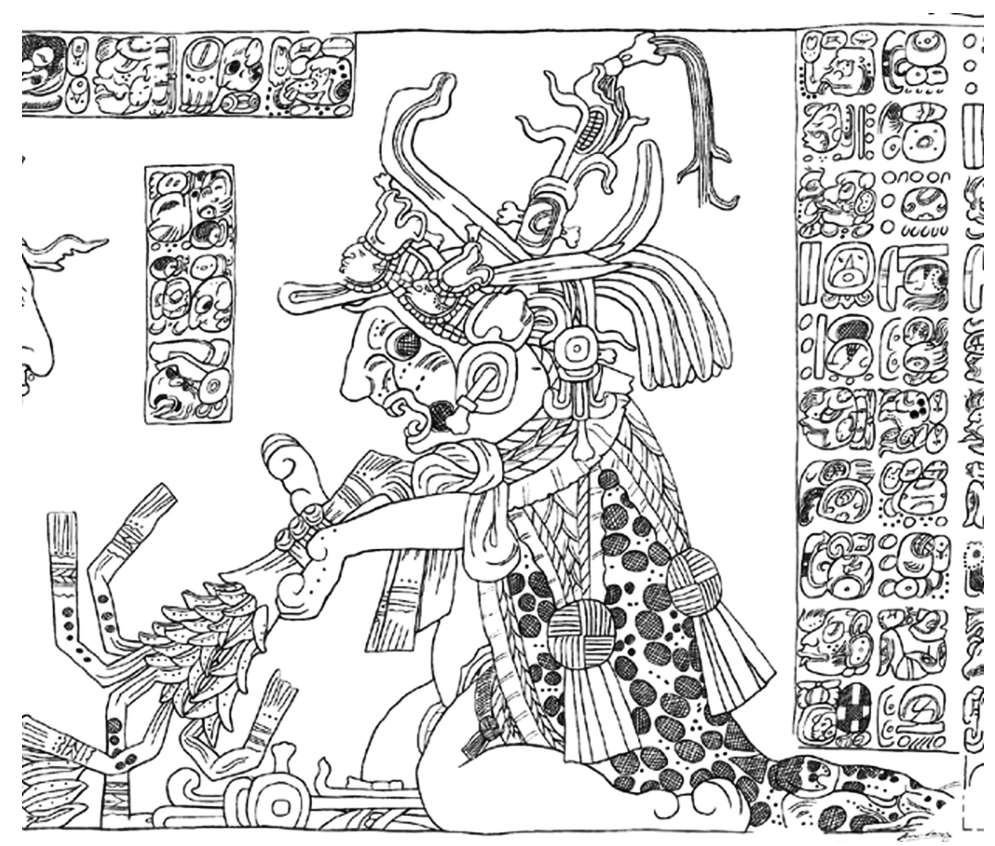

FIgura 4. Detalle del tablero del Templo XXI de Palenque. Tomado de González y Bernal, 2012: 91.

Ya en otro lugar he defendido que el Juego de Pelota puede ser entendido como una máquina para lidiar con la alteridad (Jaramillo, 2014), por eso me gustaría aquí poner otro ejemplo. En lenguas mayas parece haber una confusión entre la palabra para "año" (o más generalmente un ciclo de tiempo) y la palabra "piedra", ambas designadas con el término tun. Basado en fuentes etnohistóricas, David Stuart (1996) defiende la idea, a mi juicio acertada, de que tun no es "año", sino en efecto una piedra que se utilizaba para "conmemorar" el fin de un ciclo. "Conmemoración" no es la mejor palabra, pues remite a la idea de un tiempo abstracto del que las personas no tienen ningún control y del que sólo pueden apreciar su paso. La idea entre los mayas parece ser otra, la de un tiempo construido en el que la erección y preparación de piedras no sólo lo conmemoran, sino que lo hacen acontecer. Stuart llama a las piedras "la encarnación (embodiments) del tiempo mismo" (Stuart, op. cit., 151). Así se explica la aparente confusión entre "piedras" y "años". Algunas piedras, como verdaderas máquinas, ayudarían a los mayas a construir el tiempo, unas máquinas poderosas que necesitaban una técnica específica para hacerlas funcionar. David Stuart también identifica esta técnica. En las inscripciones de varias ciudades, este autor identifica el verbo k'al antes del glifo para tun. Esto le lleva a pensar que k'al tun es un ritual (técnica) especial que se hacía al final de ciertos períodos y que él traduce como "el atado de la piedra". Una evidencia iconográfica refuerza la idea de este k'al 
tun como una técnica aplicada en una máquina. Me refiero al cráneo de pecarí encontrado en la tumba 1 de Copán en el que se aprecia una piedra de forma cuadrada siendo atada (rodeada) por dos personajes. Vale la pena resaltar que en esta representación iconográfica, la piedra aparece siendo atada con unos motivos que recuerdan mucho al tejido de los petates, incluso de la manera que estos aparecen en los textos epigráficos y en el texto de la Estela J de Copán; puede que esta técnica de $k^{\prime} a l$ sea análoga a aquellas utilizadas en otro tipo de tejidos.

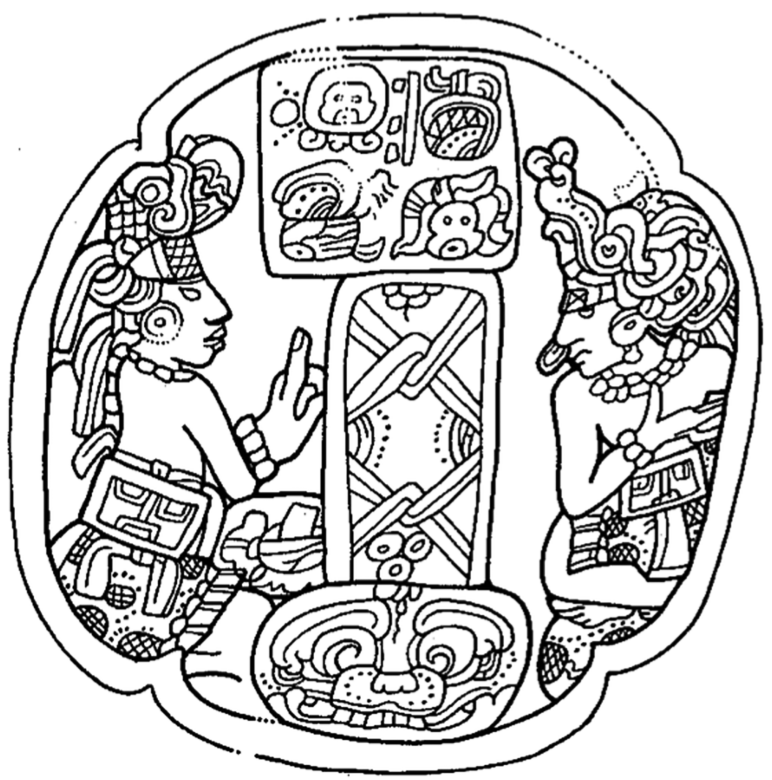

Figura 5. Cráneo de Pecarí de la Tumba 1 de Copán.

Tomado de Stuart, 1996: 156.

Arqueológicamente se han encontrado muchas piedras que, al parecer "simplemente conmemoran" el paso del tiempo. Un buen ejemplo son los llamados "discos o altares ajaw", donde a través de varias cuentas de diversos ciclos se precisa muy bien una fecha de un día ajaw (aunque existen monumentos con otros días) y su glifo aparece gigante en el medio del monumento. Es en Toniná donde se han encontrado gran parte de estos altares, muchos indican una fecha de final de período y otros la muerte y los ritos mortuorios de algunos gobernantes; en Caracol, desde el final del k'atun 2 ajaw, 9.3.0.0.0 en 495 d.C., hasta el final del k'atun 8 ajaw, 10.0.0.0.0 en 830 d.C., cada k'atun, es decir, cada 20 años, se esculpieron altares de este tipo con el objeto de registrar-crear el tiempo (Martin y Grube, 2008: 80). En Tikal también se han encontrado varios de estos famosos altares. Un disco ajaw que llama la atención por su forma y por su ubicación es el encontrado en Quiriguá (Altar L) que señala el final del k’atun 9.11.0.0.0 en 652 d.C. Aunque en su texto exterior parece un altar ajaw estándar, el día ajaw en su 
interior no está escrito en una forma tradicional, sino que está representado por la figura del mismo gobernante de Quiriguá (Martin y Grube, 2011: 216). En vez de marcadores de tiempo, estos discos debieron ser una máquina tun que sirvió para construir el tiempo, pero no conocemos cómo se llevó a cabo la técnica para hacerla funcionar.

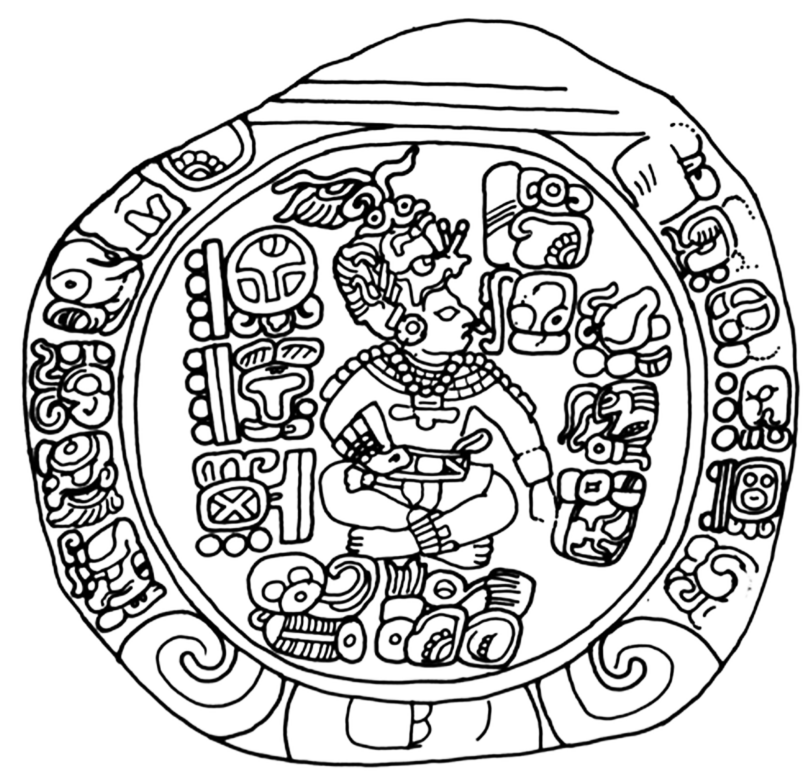

FIgURA 6. Altar L de Quiriguá.

Tomado de Martin y Grube, 2008: 217.

\section{Comentarios finales}

El panorama que aquí presento es necesariamente incompleto. Una revisión exhaustiva del régimen objetual entre los mayas del Clásico llevaría años y necesitaría de varias personas trabajando enfocadas en esto. Lo que he expuesto aquí son apenas algunas intuiciones y en esa medida es una propuesta; dejar de ver a los objetos como reflejos de una "cultura" por principio inasible e incluirlos como protagonistas de su propia historia ya sea siendo personas o como partes constitutivas de éstas, fue mi principal objetivo. Las interpretaciones puntuales me pueden ser discutidas y seguramente, con la velocidad de los hallazgos en la arqueología maya, nuevos descubrimientos harán necesaria la ampliación y ajuste de la mirada sobre los objetos en esta área. Todo ello no quiere decir que no esté seguro de lo que he expuesto: he seguido un método riguroso, he atendido a las fuentes y les he sido lo más fiel posible. No obstante, no pierdo la perspectiva y sé que todas las conclusiones son parciales. Por fortuna, cuando se trata de 
los estudios mayistas, la constante crítica y el trabajo conjunto hacen que las interpretaciones se refinen y nuestro conocimiento se profundice. Las propuestas suelen ser bien recibidas al desatar discusiones, algo que espero suceda con este escrito. Mis argumentos y las fuentes que los sustentan ya están vertidos en extenso aquí, sobra repetirlas. Prefiero, en cambio, presentar las dudas y sugerencias que me quedan para continuar el trabajo propuesto. ¿Cómo, cuándo y dónde, un mismo elemento puede pasar de ser persona a ser parte de un cuerpo o una máquina?, ¿qué marcadores objetuales se usaban para hacer la distinción entre lo propio y lo ajeno?, ¿cómo podemos acercarnos a una teoría de la invención y creación de seres y objetos de los mayas del Clásico?, ¿cómo se entablaba el parentesco con humanos y objetos?, ¿qué personas podían convertirse en ancestros y qué mecanismos se usaban para tal fin?, entre algunas otras. Para estas preguntas tengo sólo respuestas parciales o no tengo ninguna, no sé incluso si se puedan responder. Sin embargo considero que son vetas de investigación que con un trabajo cuidadoso se pueden mostrar fructíferas en un futuro próximo. No pretendo extenderme más recalcando las prevenciones necesarias sobre las conclusiones parciales de toda investigación, pues quisiera terminar con algunos apuntes respecto al método.

Al igual que procuro que las interpretaciones puntuales sean debatidas y ampliadas, considero que el método seguido en este artículo también debe ser ponderado. Erigir una arqueología recursiva que nos lleve aprender más de los mayas precolombinos de lo que podamos explicar sobre ellos es algo que considero urgente. Tomar en serio lo que nos transmiten en su escritura y en sus restos materiales es un reto que pocas veces se ha emprendido. Cuando existe alguna incompatibilidad entre lo que creemos que deba ser y lo que nos dicen las fuentes, rápidamente se lleva a condenar la información como equivocada, fantasiosa o mentirosa, o en el peor de los casos se acude a "completar" lo que apreciamos con lo que creemos saber de la sociedad maya clásica o de otra que consideramos comparable. No intento desechar la posibilidad del error o de la manipulación en las inscripciones o expresiones plásticas mayas, sin embargo deber ser la última posibilidad cuando otras alternativas ya hayan sido exploradas y rechazadas. Vale la pena hacer el esfuerzo por comprender lo que desde nuestra visión nos parece imposible aceptando que la construcción de realidad de los mayas es radicalmente diferente a la nuestra. Las preguntas que nos ayuda a responder la arqueología maya son de manera invariable nuestras, pero podemos aprender a hacer preguntas que sean sugeridas y co-producidas por las personas (humanas y no humanas) con las que trabajamos.

\section{BIBLIOGRAFÍA}

Appadurai, Arjun (ed.)

1991 La vida social de las cosas. Perspectiva cultural de las mercancías. México: Grijalbo y Consejo Nacional para la Cultura y las Artes. 
Argucia Fasquelle, Ricardo y Bárbara Fash

2005 "The Evolution of Structure 10L-16, Heart of the Copán Acropolis", Copán. The History of an Ancient Maya Kingdom, pp. 201-237, Wyllys Andrews y William Fash (eds). Santa Fe: School of American Research Press.

Bernal, Guillermo

2011 "El señorío de Palenque durante la era de K'inich J'anaahb Pakal y K'inich K'an Ba'lam (615-702d.C.)”, tesis de Doctorado en Estudios Mesoamericanos. México: Universidad Nacional Autónoma de México.

Bordieu, Pierre

1997 Razones prácticas sobre la teoría de la acción. Barcelona: Anagrama.

Cadena, Marisol de la

2010 "Indigenous Cosmopolitics in the Andes: Conceptual Reflections beyond "Politics”, Cultural Anthropology, 25 (2): 334-370.

Cavalcante Gomes, Denise Maria

2010 "Os contextos e os significados da arte cerâmica dos Tapajó", Arqueologia Amazônica, t. I, pp. 213-234, Edithe Pereira y Vera Guapindaia (orgs.). Belem: Museu Emílio Goeldi.

Chase, Diane Zaino y Arlen Frank Chase

1998 "The Architectural Context of Caches, Burials, and Other Ritual Activities for the Classic Period Maya (as Reflected at Caracol, Belize)", Function and Meaning in Classic Maya Architecture, pp. 299-332, Stephen Douglas Houston (ed.). Washington, D.C.: Dumbarton Oaks Research Library and Collection.

Christenson, Allen J.

s.f. Weaving the Fabric of the Cosmos, < http://www.mesoweb.com/features/fabric/ textindex.html $>$ [Consultada el 21 de febrero del 2015].

Dayley, Jon Phillip

1985 Tzutujil grammar. Berkeley: University of California Press (University of California Publications in Linguistics, 107).

Erikson, Phillipe

1996 El sello de los antepasados. Marcado del cuerpo y demarcación étnica entre los matis de la Amazonía. Quito: Abya Yala.

Gell, Alfred

1998 Art and Agency. An Anthropological Theory. Oxford: Claredon Press.

Gillespie, Susan Dale

2001 "Personhood, Agency, and Mortuary Ritual: A Case Study from the Ancient Maya”, Journal of Anthropological Archaeology, 20: 73-112.

2008 "Aspectos corporativos de la persona (personhood) y la encarnación (embodiment) entre los mayas del período Clásico", Estudios de Cultura Maya, XXXI: 65-89. 
González, Arnoldo y Guillermo Bernal

2012 "El descubrimiento del monumento del Templo XXI, en Palenque: el reino de Baakal durante el reinado de K'inich Ahkal Mo' Nahb”, Maya Archaeology 2: 82-103.

Hanks, William

1986 Intertexts: Writings on Language, Utterance and Context. Oxford: Rowman and Littlefield.

Henare, Amiria, Martin Holbraad y Sari Wastel

2007 Thinking Through Things. Theorising Artefacts Ethnographically. Londres: Routledge.

Hendon, Julia

2012a "Objects as Persons. Integrating Maya Beliefs and Antropological Theory", Power and Identity in Archaeological Theory and Practice, Case Studies from Ancient Mesoamerica, pp. 82-89, Eleanor Harrison-Buck (ed.). Salt Lake City: The University of Utah Press.

2012b "Neighborhoods in Pre-Hispanic Honduras. Settlement Patterns and Social Groupings Within Sites or Regions", The Neighborhood as a Social and Spatial Unit in Mesoamerican Cities, pp. 159-180, Charlotte Aranauld, Linda Manzanilla y Michael Smith (eds.). Arizona: University of Arizona Press.

Hodder, Ian

2012 Entangled: An Archaeology of the Relationships Between Humans and Things. Nueva York: Wiley-Blackwell.

Houston, Stephen y David Stuart

2008 "El glifo way: evidencia de la existencia de 'coesencias' entre los mayas del [1989] período Clásico / The Way Glyph: Evidence for Co-essences among the Classic Maya”. Washington, D.C.: Center for Maya Research. (Research Reports on Ancient Maya Writing 30), <www.mesoweb.com/bearc/cmr/RRAMW30es.pdf $>$ [Consultada el 21 de febrero del 2015].

Jaramillo, Antonio

2014 "La cuenca del Caribe como Unidad Diversa: el Juego de Pelota, una máquina para lidiar con la alteridad", Sistemas políticos, relaciones internacionales e identidades. Memorias III Congreso Internacional de Estudios Caribeños, pp. 228254, Raúl Román Romero, Jorge Elías Caro y Antonino Vidal (comps.). San Andrés Isla: Universidad Nacional de Colombia, sede Caribe.

Kirchhoff, Paul

2009 Mesoamérica. Sus límites geográficos, composición étnica y caracteres culturales, [1943] Xalapa: Al fin liebre ediciones digitales.

Kroeber, Albert Louis

1939 Cultural and Natural Areas of Native North America. Berkeley: University of California (Publications in American Archaeology and Ethnology). 
Lagrou, Els

2012 "Um corpo feito de artefatos: o caso da miçanga", <http://es.scribd.com/ doc/174094854/2012-Lagrou-micanga-Cahiers-Fausto-e-Severi $>$ [Consultada el 21 de febrero del 2015].

Latour, Bruno

2008 Reensamblar lo social. Una introducción a la teoría del actor-red. Buenos Aires: Editorial Manantial.

Lehmann, Christian

2002 Posesion in Yucatec Maya, <http://www.christianlehmann.eu/ling/sprachen/ maya/gramatica/onomas/posesion/index.html?http://www.christianlehmann. eu/ling/sprachen/maya/gramatica/onomas/posesion/partes_cuerpo.html> [Consultada el 21 de febrero del 2015].

Martin, Simon y Nikolai Grube

2008 Chronicle of Maya Kings and Queens. Nueva York: Thames and Hudson.

Martínez, Isabel

2009 "Eduardo Viveiros de Castro: de imaginación, traducción y traición", Anales de Antropología, 41 (II): 239-262.

2012 "Alteridad, multiplicidad y reversibilidad en clave rarámuri. Crónica de un viaje por la antropología del otro", tesis de Doctorado en Antropología. México: Universidad Nacional Autónoma de México, Instituto de Investigaciones Antropológicas.

Martínez de Velasco Cortina, Alejandra

2012 "Contextos arqueológicos de las vasijas matadas del Área Maya”, XXV Simposio de Investigaciones Arqueológicas en Guatemala, 2011, pp. 1207-1221, Bárbara Arroyo, Lorena Paiz y Héctor Mejía (eds.). Guatemala: Ministerio de Cultura y Deportes, Instituto de Antropología e Historia y Asociación Tikal.

Miller, Daniel

2009 "Materialidad: una introducción”, traducción de Andrés Laguens del texto original "Materiality: An Introduction", Materiality, pp. 1-50, Daniel Miller (ed.), Durham, N.C.: Duke University Press, <http://es.scribd.com/doc/32872168/ Daniel-Miller-Materialidad $>$ [Consultada el 21 de febrero del 2015].

Neurath, Johannes

s.f. "Lo dado y lo soñado", La humanidad compartida, pp: 1-19, Carlo Bonfiglioli, Isabel Martínez y Alejandro Fujigaki (eds.). México: Universodad Nacional Autónoma de México, Instituto de Investigaciones Antropológicas, $<$ http:// www.iia.unam.mx/images/difusion/Taller_Signos de Mesoamrica/lecturas/ Neurath-LoDadoYloSonado.pdf > [Consultada el $2 \overline{1}$ de febrero del 2015].

2008 "Alteridad constituyente y relaciones de tránsito en el ritual huichol: iniciación, anti-iniciación y alianza”, Cuicuilco, 15 (42): 29-44.

2013 La vida de las imágenes. Arte huichol. México: Artes de México y Consejo Nacional para la Cultura y las Artes. 
Novotny, Anna C.

2013 "The Bones of the Ancestors as Inalienable Possessions: A Bioarchaeological Perspective", Archeological Papers of the American Anthropological Association, 23: 54-65.

Oudijk, Michel

2008 "De tradiciones y métodos: investigaciones pictográficas", Desacatos, 27: 123-138.

Pitarch, Pedro

2013 La cara oculta del pliegue. Antropología indígena. México: Artes de México.

Reents-Budet, Dorie

2010 "Las narrativas pictóricas y jeroglíficas en los monumentos de Copán”, Manual de los monumentos de Copán, Honduras, pp 46-54, Ricardo Agurcia Fasquelle y Vito Veliz (eds.). Asociación Copán, <http://www.famsi.org/spanish/research/ copan/monuments/index.html> [Consultada el 21 de febrero del 2015].

Renfrew, Colin y Paul Bahn

1993 Arqueología. Teoría, métodos y práctica. Madrid: Akal.

Santos-Granero, Fernando (ed.)

2009 The Occult Life of Things. Native Amazonian Theories of Materiality and Personhood. Arizona: Tucson y University of Arizona Press.

Schumman, Otto

1997 Introducción al maya mopán. Los itzáes desde la época prehispánica hasta la actualidad: estudio interdisciplinario de un grupo maya. México: Universidad Nacional Autónoma de México, Instituto de Investigaciones Antropológicas.

Strathern, Marilyn

1988 The Gender of the Gift. Problems with Women and Problems with Society in Melanesia. Berkeley: University of California Press.

1995 The Relation: Issues in Complexity and Scale. Cambridge: Prickly Pear Press.

Stuart, David

1989 "Los jeroglíficos de la vasijas mayas", traducción de "Hieroglyphs on Maya Vessels", The Maya Vase Book: A Corpus of Rollout Photographs of Maya Vases, 1: 149-160, <http://www.mesoweb.com/es/articulos/Stuart/Jeroglificos.pdf> [Consultada el 21 de febrero del 2015].

1996 "Kings of Stone. A Consideration of Stelae in Ancient Maya Ritual and Representation", RES: Antropology and Aesthetics, 29-30: 148-171.

2012a "Notas en torno a un nuevo texto de La Corona”, Mesoweb, <www.mesoweb. com/es/articulos/Stuart/LaCorona. html> [Consultada el 21 de febrero del 2015]

2012b “On Effigies of Ancestors and Gods", Maya Deciphrement. Ideas on Ancient Maya Writing and Iconography, <https://decipherment.wordpress.com/2012/01/20/ on-effigies-of-ancestors-and-gods/> [Consultada el 21 de febrero del 2015]. 
Suzuki, Shintaro, Vera Tiesler y Andrea Cucina

2011 "Nuevas estrategias en la evaluación de la edad a la muerte en poblaciones esqueléticas: la histomorfología de dignatarios mayas de México (Calakmul, Ek’ Balam) y del sureste de Petén (Atlas Arqueológico)", XXIV Simposio de Investigaciones Arqueológicas en Guatemala, 2010, pp. 1077-1087, Bárbara Arroyo, Lorena Paiz y Héctor Mejía (eds.). Guatemala: Ministerio de Cultura y Deportes, Instituto de Antropología e Historia y Asociación Tikal.

Taylor, Anne Christine

2005 "Las máscaras de la memoria. Ensayo sobre las pinturas corporales jívaro", Chamanismo y sacrificio, pp. 299-333, Jean-Pierre Chaumeil, Roberto Pineda Camacho y Jean François Bouchard (eds.). Lima: Instituto Francés de Estudios Andinos.

Velásquez, Erik

2011 "Las entidades y fuerzas anímicas en la cosmovisión maya clásica”, Los mayas. Voces de piedra, pp. 235-253, Alejandra Martínez y María Elena Vega (coords.). México: Ámbar.

Viveiros de Castro, Eduardo

2004 "Exchanging Perspectives: The Transformation of Objects into Subjects in American Ontologies", Common Knowledge, 10 (3): 463-483.

2013 La mirada del jaguar. Introducción al perspectivismo amerindio. Entrevistas. Buenos Aires: Tinta Limón.

Welsh, W. B. M.

1998 An Analysis of Classic Lowland Maya Burials. Oxford: BAR (Publication 8 / International Series 409).

Wisdom, Charles

1950 Chorti Dictionary, transcrito y transliterado por Brian Stross. Austin: Universidad de Texas.

Wright, Lori

2005 "In Search of Yax Nuun Ayiin I. Revisiting the Tikal Project's Burial 10", Ancient Mesoamerica, 16: 89-100. 